\title{
Wastewater Treatment Methods and Sewage Treatment Facilities in Almaty, Kazakhstan
}

\author{
Kairat Ospanov ${ }^{1 *}$, Erzhan Kuldeyev², Bagdaulet Kenzhaliyev³ ${ }^{3}$ Anatoly Korotunov ${ }^{4}$ \\ 1 Satbayev University, KR 050013 Almaty, Satbayev str. 22, Kazakhstan \\ 2 Institute of Metallurgy and Ore Beneficiation, Stabayev University KR 050010 Almaty, \\ Shevchenko str. 29/133, Kazakhstan \\ ${ }^{3}$ Institute of Metallurgy and Ore Beneficiation, Stabayev University KR 050010 Almaty, \\ Shevchenko str. 29/133, Kazakhstan \\ ${ }^{4}$ Water Disposal Department, State Utility Company “Almaty Su”, KR 050057 Almaty, Zharokovkова str.196, \\ Kazakhstan \\ * Corresponding author's e-mail: ospanovkairat@mail.ru
}

\begin{abstract}
The results of comprehensive research on the status of sewage treatment in Almaty are presented in this article. The results of the reconstruction and modernization of treatment facilities intended to improve the sewage treatment efficiency, including the results of pretreatment of wastewater with excess sludge in the primary clarification tank, and the results of hydrobiological and microbiological analysis of activated sludge in the aeration tank are presented. The analysis of the study results of the chemical composition of incoming, clarified and treated wastewater is presented. Besides, the results of the analysis of the water balance of wastewater are presented.
\end{abstract}

Keywords: wastewater, sedimentation tanks, aeration tanks, water quality, wastewater storage.

\section{INTRODUCTION}

The state of the environment and its components increasingly affects economic development, health, and life expectancy. Protection of the environment and, especially, water bodies from pollution and depletion is one of the most important tasks in the modern world. [Environmental Code of RK 2001, Directive 2000/60/EC]. Discharge of untreated and insufficiently treated wastewater into surface water bodies constantly worsen their condition. A further uncontrolled increase in the anthropogenic load on natural resources can lead to a global disruption of the natural balance that will entail the destruction of the natural balance of human life. This necessitates the design and construction of wastewater treatment plants that meet the pollution abatement targets set by the state environmental protection agencies. The scale of the forthcoming work in this direction requires a serious justification of the decisions made and determines the number of specific problems related to wastewater disposal and treatment.

Currently, wastewater treatment is performed according to the classical scheme, including mechanical treatment on grids, in sand traps and primary sedimentation tanks, biochemical treatment in aeration tanks with subsequent sedimentation in secondary sedimentation tanks, disinfection of wastewater, and in some cases additional treatment by different methods in most municipal sewage treatment plants of Kazakhstan. Most of the sewage treatment plants were designed and built in the 1960s and 1980s. As a rule, the design capacity of the sewage treatment plants was based on the development of the city's industry. However, at present, with the transition to new management methods, the construction of new industrial plants has been drastically reduced, the production capacity of the number of plants has decreased, and some plants have implemented their local facilities. 
Besides, due to the use of modern sanitation devices, water meters, the amount of domestic wastewater coming to the wastewater treatment plant from the population has decreased. All this has led to a decrease in the capacity of the plant, a change in the quality composition of wastewater relative to the design data. The significant difference between design and actual values at many treatment plants led to some violations of the technological mode of treatment facilities that is reflected in the unsatisfactory quality of treated wastewater. Similar problems were encountered at the biological treatment plant in Almaty.

At the same time, the financial component becomes a key issue in a market economy, when the technology laid down in the process is selected. Due to the current socio-economic conditions in Kazakhstan, most organizations involved in wastewater treatment experience a shortage of funds for the operation, modernization, and even more so for the construction of new high-tech wastewater treatment plants. Nevertheless, work is being performed in this direction.

At the same time, previous biological and mechanical wastewater treatment is changing in recent years [Chen J. et al. 2018]. It is considered progressive to extract the wastewater and remove it from the wastewater treatment cycle with further disposal.

Many economically and technically developed states have nowadays abandoned the use of sludge beds posing a threat to the environment as sludge beds are an environmental problem, both present and in the long term. The implementation of engineering measures for the return of land withdrawn from circulation within the city has, in addition to environmental importance, a high economic and social significance: sludge should be removed, processed, and safely disposed of, and the freed territory should be re-cultivated for housing construction or other rational use [Werther J. et al. 1999].

The required degree of removal of suspended solids in mechanical treatment plants depends on the initial content of suspended solids in the wastewater. The optimum detention effect is considered $60-150 \mathrm{mg} / 1$ of suspended solids in the wastewater fed into the aeration tank [Zhmur N.S. 2003]. One of the main objectives of high-quality wastewater treatment is to ensure that the sedimentation process in the primary sedimentation tank is organized as efficiently as possible and the biological treatment section receives wastewater containing only dissolved organic contaminants [Droste R. et al. 2019].

The recirculation of activated sludge biomass from secondary sedimentation tanks to the primary sedimentation tank is made to maintain the required concentration of activated sludge in the aeration plant and to ensure that it has sufficient oxidation capacity. Partial return of activated sludge to the head of the wastewater treatment process line is also necessary to enable adsorption of pollutants that oversaturate the wastewater and thereby ensure sustainable and reliable operation of aeration tanks [Lovett D.A. et al. 1984].

At the same time, the effectiveness of biological wastewater treatment is determined by the operation of secondary sedimentation tanks that must ensure the separation of activated sludge from the treated water. The higher the efficiency of the secondary clarifier, the higher the concentration of return sludge and the lower the recirculation rate has to be in the aeration tank. Unlike raw sludge, activated sludge is more sensitive to sludge deposits that require a more sophisticated sludge collection and pumping system from the bottom of the tank and the sedimentation tanks [Burger R. et al. 2011, Andreev S.Yu. et al. 2006].

During the operation of secondary sedimentation tanks, it is very important to establish and maintain an optimum sludge bed height. In winter, the sludge layer height can be $25 \%$ of the sedimentation tank depth, and in summer not more than $10 \%$. When sludge accumulates in the lagoons and the optimal sludge bed height is exceeded, the return sludge humidity decreases, but its concentration increases that can contribute to excessive sediment removal. Excessive retention time and excessive circulation of excess sludge in the sedimentation tank result in higher excess sludge humidity that in turn increases the amount of sludge handling and disposal facilities [Zhmur N.S. 2003, Vaxelaire J. et al. 2004].

In other words, if more than the optimum amount of sludge is removed from the secondary sedimentation tank, excess sludge is returned to the aeration tank; if less, much more settled sludge is collected in the sedimentation tank, and the quality of the treated water decreases.

Measures to optimize the operation of the Almaty wastewater treatment plant will be considered in this paper. 


\section{MATERIALS AND METHODS}

Almaty is a city of national importance and the largest population center in the Republic of Kazakhstan, the former capital of Kazakhstan. The official population of the city at the beginning of 2020 was 1916822 people. The climate is continental and characterized by a mountainvalley circulation that is particularly evident, in the northern part of the city, located directly in the transition zone of mountain slopes to the plains. The long-term average air temperature is $+10{ }^{\circ} \mathrm{C}$, the coldest month (January) $-4.7^{\circ} \mathrm{C}$, the warmest month (July) $+23.8^{\circ} \mathrm{C}$ [Material from Wikipedia 2020].

The State Municipal Enterprise "Almaty Su" provides services in the Almaty water supply and sanitation system. The objective of the enterprise is to operate sewerage networks and facilities and provide services of reception, diversion, treatment, discharge of wastewater, and waste disposal [Technological regulations 2013]. The enterprise was established for providing sewerage services, and its functions are:

- maintenance, current and overhaul repair, operation of sewerage networks, treatment plants, pumping stations, and diversion channels;

- discharge of effluents under standards;

- development and implementation of measures to improve economic efficiency and work technology;

- other activities not prohibited by legislation, under the procedure established for stateowned subsidiaries on the right of economic management.

According to historians and archaeologists, the first sewage networks appeared in 1935. In the same year, the construction of sewers started. A street network was also developed, in which wastewater was diverted to irrigation fields. The length of the sewerage network was $42 \mathrm{~km}$ [Technological regulations 2013].

At present, Almaty's sewerage system operates on an incomplete split system, one of which is a stormwater (irrigation canal) system - with diversion of water into small rivers - and another city-wide system for industrial and domestic wastewater. The outdoor sewer network runs along all the main streets of the city. The length of sewer networks is $1.562 \mathrm{~km}$, including $-177 \mathrm{~km}$ of sewers ( 800 to $2.000 \mathrm{~mm}$ diameter), $646 \mathrm{~km}$ of street networks (300 to $800 \mathrm{~mm}$ diameter), and
$738 \mathrm{~km}$ of indoor networks (under 100 to $300 \mathrm{~mm}$ diameter). The main collectors running south to north with pipe diameters ranging from 600 to $1500 \mathrm{~mm}$ and burial depths from 1.5 to $7.0 \mathrm{me}-$ ters, and then the suburban collectors with rectangular cross-sections from $1300 \times 1800$ to $1800 \mathrm{x}$ $2000 \mathrm{~mm}$, transport the sewage to the municipal sewage treatment plant.

The wastewater treatment facilities of the city of Almaty are located $12 \mathrm{~km}$ northwest of the city border, in the Iliysk district of Almaty oblast, south-west of Zhapek Batyr settlement, on the banks of Bolshaya Almatinka River. The design (planned) capacity of the mechanical and biological treatment facilities is 640 thousand $\mathrm{m}^{3}$ per day.

Year of beginning and end of the construction phase:

- mechanical treatment the $1^{\text {st }}$ phase is 1965-1970,

- mechanical treatment the $2^{\text {nd }}$ phase is 1971-1974,

- biological treatment the $1^{\text {st }}$ phase is 1974-1980,

- biological treatment the $2^{\text {nd }}$ phase is 1980-1992.

The Almaty city wastewater entering the city sewerage system is treated at the aeration station that consists of three workshops: mechanical treatment, biological treatment, and wastewater diversion workshop [20]. The mechanical treatment plant is located on the right bank and the biological treatment plant on the left bank, outside the coastal water protection zone (Figure 1). Nine strings of the Almaty culvert interconnect the mechanical and biological treatment facilities. The elevation of the structures ensures the gravity flow of the main masses of wastewater, making use of the natural topography of the area.

The plant performs mechanical and full artificial biological wastewater treatment. In case of an emergency shutdown of treatment facilities, the possibility is provided to discharge the whole volume of wastewater through the Burunday emergency discharge canal to an emergency tank with a volume of 1.5 million $\mathrm{m} 3$ and filtration fields with a total area of 1029.4 ha, located $12 \mathrm{~km}$ to the north of the Aeration station [Technological regulations 2013].

Biologically treated wastewater through a discharge channel is discharged into the Sorbulak storage lake or into the system of ponds and reservoirs of the Right Bank Sorbulak Canal (RBSC), where part of the effluent through an emergency 


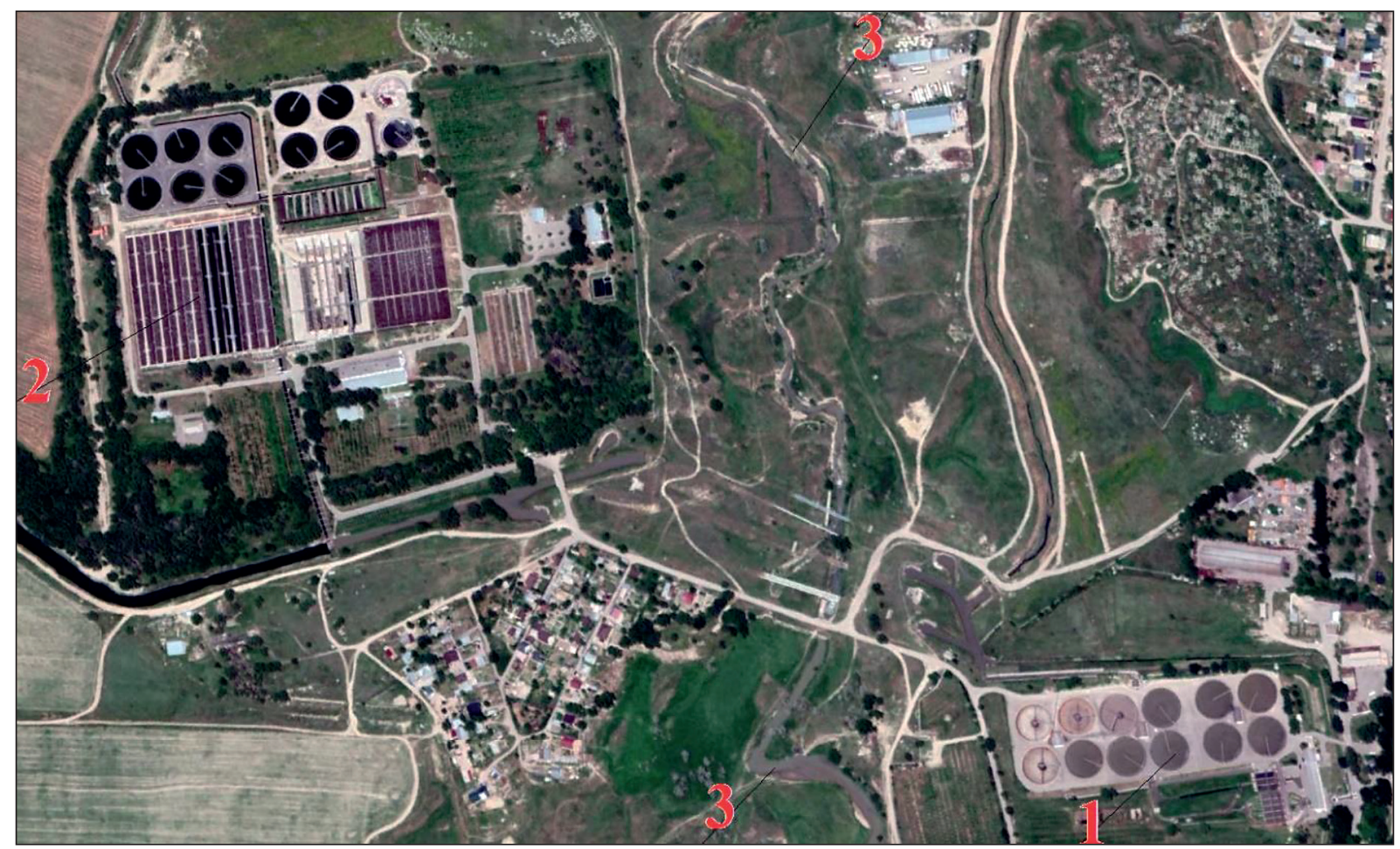

Fig. 1. Appearance of the sewage treatment plant:

1 - Mechanical treatment plant; 2 - Biological treatment plant; 3 - Bolshaya Almatinka River

discharge channel, through bio-ponds can be discharged into the Ili River. Technological scheme of the sequence of stages of wastewater treatment is shown in Figure 2.

During the operation of the plant, the necessary current and overhaul repair of treatment facilities and technological equipment is performed. The territory of the aeration station has all necessary administrative, laboratory, household, and service buildings and premises, including repair and mechanical workshops, garages, pumping stations, and storage facilities. The aeration station treatment facilities operate continuously around the clock, treating all wastewater from the city and its suburbs to the required degree of purification.

\section{RESULTS AND DISCUSSION}

Wastewater is delivered to the treatment plant via three suburban collectors with a diameter of $d$ $=1500 \mathrm{~mm}$ and the Burunday collector with a diameter of $d=1000 \mathrm{~mm}$. The actual annual volume of wastewater from Almaty to the aeration plant has been increasing over the years (due to urban growth, industrial development, etc.) and reached its maximum in 1990. In 1990, 212.88 million $\mathrm{m}^{3}$ of wastewater (583 thousand $\mathrm{m}^{3}$ a day on average) was discharged through the plant. However, in the following years, the volume of wastewater decreased. The amount of wastewater (in thousand $\mathrm{m}^{3}$ ), passed through mechanical treatment at the aeration plant for the period 2005-2020 is given in Figure 3.

It can be seen in Figure 3 that during the period 2005-2020 the amount of wastewater averaged - 362.15 thousand $\mathrm{m}^{3}$ per day (132186.362 thousand $\mathrm{m}^{3 /}$ year). And the actual annual volume of wastewater treated in 2020 was 132287.737 thousand $\mathrm{m}^{3 /}$ year, i.e. 362.432 thousand $\mathrm{m}^{3 /}$ day on average.

A receiving chamber is used to equalize the velocities, and to distribute the effluent evenly over the operating grids. From the chamber, wastewater is routed through reinforced concrete channels to the grates. The wastes trapped on the grids are hydro-washed into a special container, disinfected with a chlorine lime solution, and transported together with the municipal solid waste to be disposed of by specialized organizations.

Heavy solids are captured in horizontal sand traps. The precipitated solids and sand are transported hydraulically to the pit, from where they are pumped to the sand pads by hydro-elevators. After the sand trap, the wastewater flows to the 


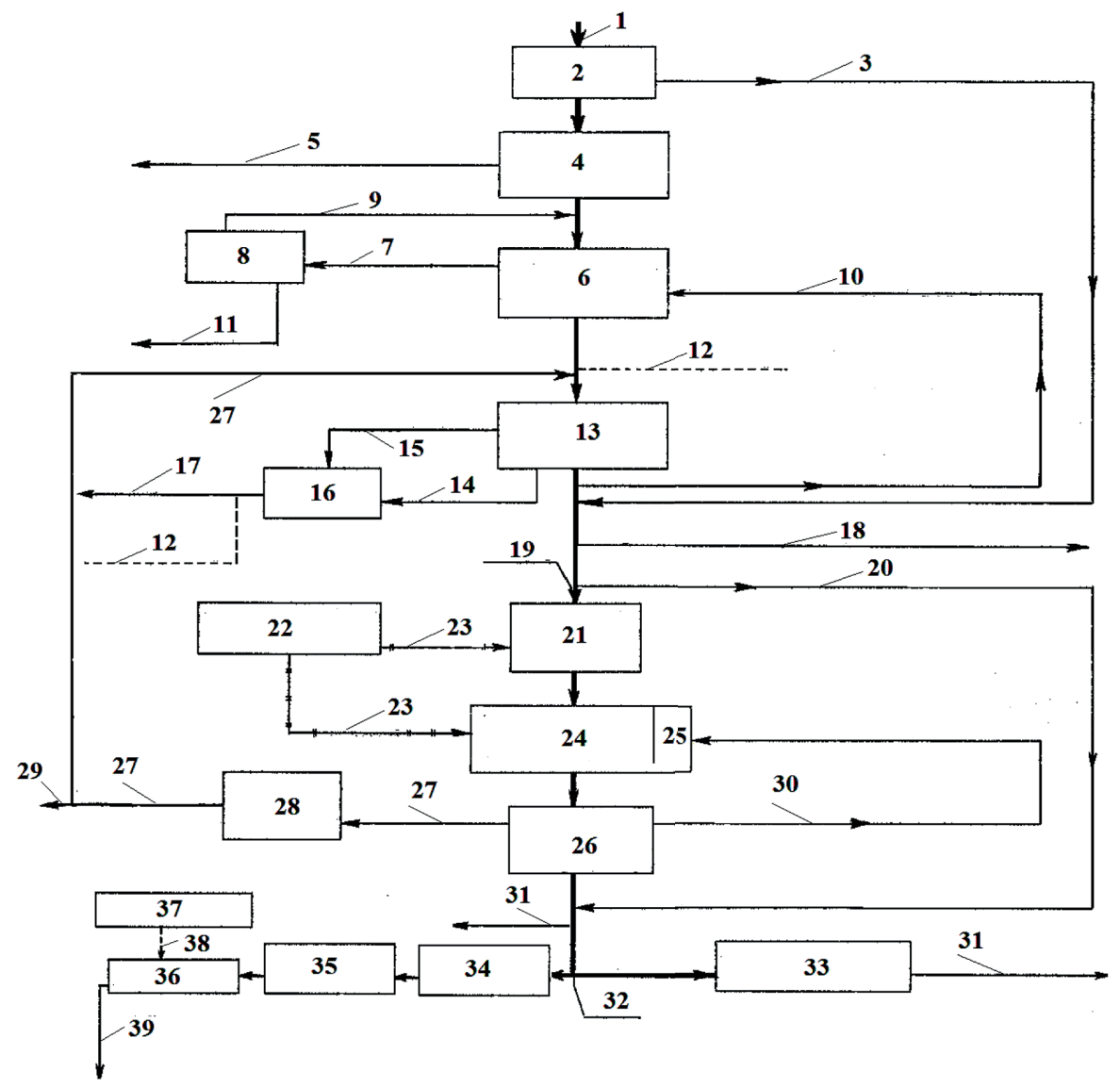

Fig. 2. Technological scheme of the sequence of stages of wastewater treatment:

1 - wastewater inlet; 2 - receiving chamber; 3 - diversion canal; 4 - grids; 5 - sludge platforms; 6 - sand catcher; 7 - sand; 8 - sand platforms; 9 - drainage water; 10 - clarified water for hydraulic disposal; 11 - sand for use 12 - flow meter; 13 - primary sedimentation tanks; 14 - raw sludge; 15 - floating grease; 16 - pumping station; 17 - sludge to sludge beds; 18 - discharge channel; 19 - sluice-regulator; 20 - emergency discharge; 21 - aerlift pumping station 22 - blower station; 23 - compressed air; 24 - aeration tank; 25 - regenerator; 26 - secondary sedimentation tanks; 27 - excess activated sludge; 28 - main pumping station; 29 - excess activated sludge to sludge platforms; 30 - return activated sludge; 31 - water for irrigation; 32 - water divider; 33 - Sorbulak storage; 34 - storage tanks of Right Bank Sorbulak Canal (RBSC); 35 - biological treatment ponds; 36 - mixer; 37 chlorination plant; 38 - chlorine; 39 - discharge into the Ili River.

primary sedimentation basin through a common chute, where it is quantified, into the distribution bowl. The removal of suspended solids that can settle or float by gravity, from the wastewater takes place in the primary radial sedimentation tanks. The raw sludge deposited in each sedimentation tank is moved to a pit from which it is pumped to the sludge beds by scrapers installed on the sludge scraper farm. Sludge removal is performed 1-3 times a day depending on the specific conditions under a pumping schedule to be established for a specific period. The average moisture content of the discharged sludge is $97 \%$. Table 1 shows the particle size distribution obtained by screening the sewage sludge before discharge to the sludge beds.
Currently, only sludge pads are used to treat sewage sludge. The sludge pads of the aeration station are designed for natural dehydration, storage, disposal of these sediments. Sludge pads with reserve emergency pads are located on the right bank of the Bolshaya Almatinka river valley in the Ili district of the Almaty region. They are located $12 \mathrm{~km}$ north of the aeration station, with a total area of 123 hectares. The sludge beds are elongated in the plan by a narrow strip from south to north and are made on a natural foundation without drainage. The sites are located on loess-like loams of varying thickness from 5 to 20 meters. Loams have subsidence properties of the 1 st and 2 nd types in some areas. The maximum height of the dams is from 3 to 4.4 meters, 
Table 1. Granulometric composition of sewage sludge

\begin{tabular}{|c|c|c|c|c|c|c|}
\hline \multirow{2}{*}{ Humidity, \% } & \multicolumn{6}{|c|}{ Fraction content, \% } \\
\cline { 2 - 7 } & $1250 \mu \mathrm{m}$ & $630 \mu \mathrm{m}$ & $315 \mu \mathrm{m}$ & $160 \mu \mathrm{m}$ & $80 \mu \mathrm{m}$ & $<40 \mu \mathrm{m}$ \\
\hline 97 & 8.52 & 13.86 & 20.63 & 24.44 & 30.5 & 2.05 \\
\hline
\end{tabular}

the width of the enclosing dams along the ridge is 6 meters, the dividing dams are 4.5 meters. The distance from the extreme maps to the nearest water body of the Bolshaya Almatinka River is 300-500 meters; groundwater is located at a depth of 4-6 meters. Figure 4 shows pictures of the sludge beds.

We collected water samples for analysis at five locations adjacent to the sludge beds. The sampling points are shown in Figure 5: 1 point Bolshaya Almatinka River up to the sludge sites; 2 point - Bolshaya Almatinka River after the sludge sites; 3 point - groundwater $150 \mathrm{~m}$ from the sludge sites; 4 point - groundwater $200 \mathrm{~m}$ from the sludge sites; 5 point - groundwater $10 \mathrm{~m}$ from Bolshaya Almatinka River.

The results of the analyses of the main water quality indicators are shown in Table 2 .

The results of the analysis show that groundwater from the areas adjacent to the sludge beds has a high level of contamination. Water from the sludge beds to some extent pollutes the water of the Bolshaya Almatinka River with various chemical elements. Some indicators of water of the Bolshaya Almatinka River after the sludge sites according to the regulatory requirements "Rules of surface water protection of the Republic of Kazakhstan," do not meet the Maximum Allowable Concentration standards for fishery water body [Guiding normative document 01.01.03-94 RK 1994].
After settling in the sedimentation tank, the clarified wastewater is then collected in a common channel and sent to the biological treatment plant. That is, the wastewater via a receiving concrete channel enters the pump chambers, from where it is pumped to the aeration tanks by Flygt axial pumps. Air from a blower station is fed into the tanks to support microbial life and to purify the wastewater in the aeration tanks. The mixture of treated effluent and activated sludge after the aeration tanks is collected in the sludge mixture channel of the secondary sedimentation tanks. In the secondary sedimentation tanks, activated sludge settles and through the sludge chambers and then, by Flygt axial pumps, is pumped into the sludge channel of aeration tanks, from where it is partially returned to aeration tanks.

Due to current socio-economic conditions, the known methods of intensification of wastewater treatment processes are not always possible to implement in Kazakhstan for technical and economic reasons. Nevertheless, work is being performed in this direction. As noted above, an analysis of the available treatment plant material shows that an efficient and sustainable biochemical process in aeration tanks can be ensured when the effluent fed to them has an optimum concentration of contaminants. The partial return of excess activated sludge to the primary sedimentation tank ensures the necessary concentration of activated sludge in the aeration tank and its sufficient oxidation

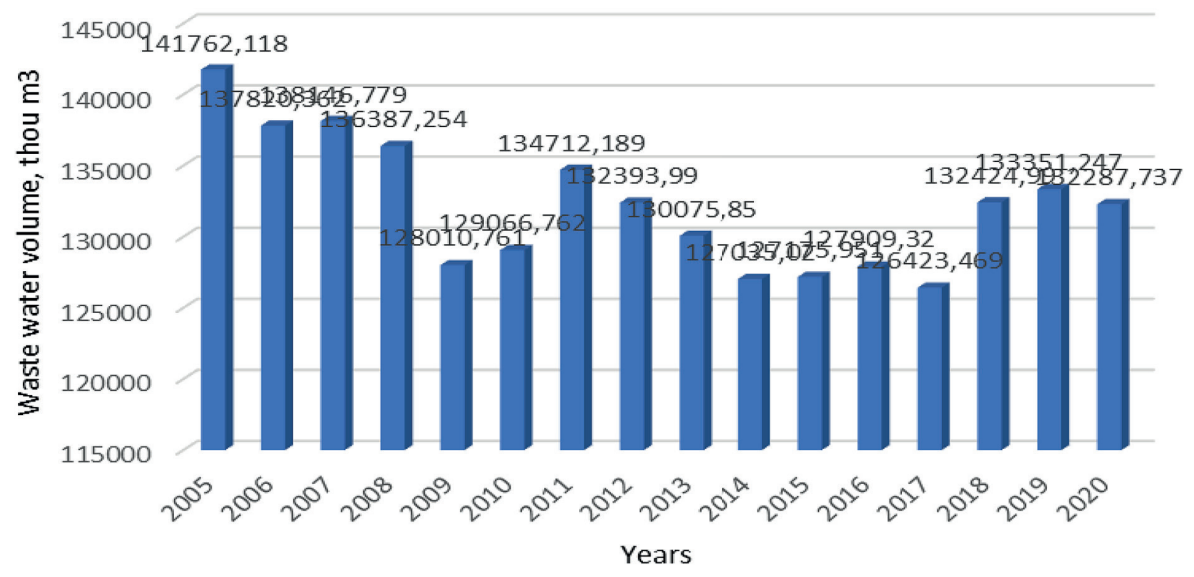

Fig. 3. Quantity of wastewater (in thousand $\mathrm{m}^{3}$ ) passed through mechanical treatment in the aeration plant for the period 2005-2020 


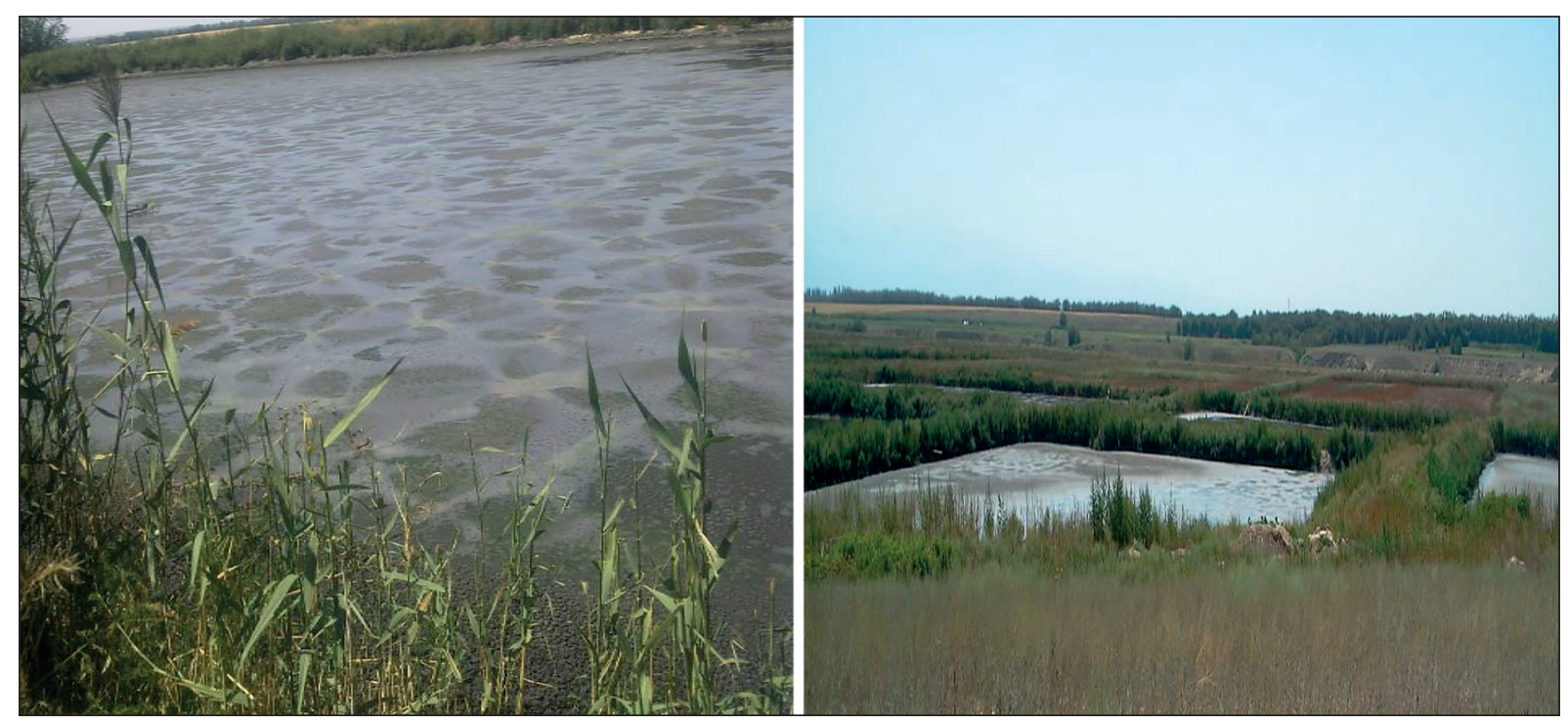

Fig. 4. Photographs of the sludge beds

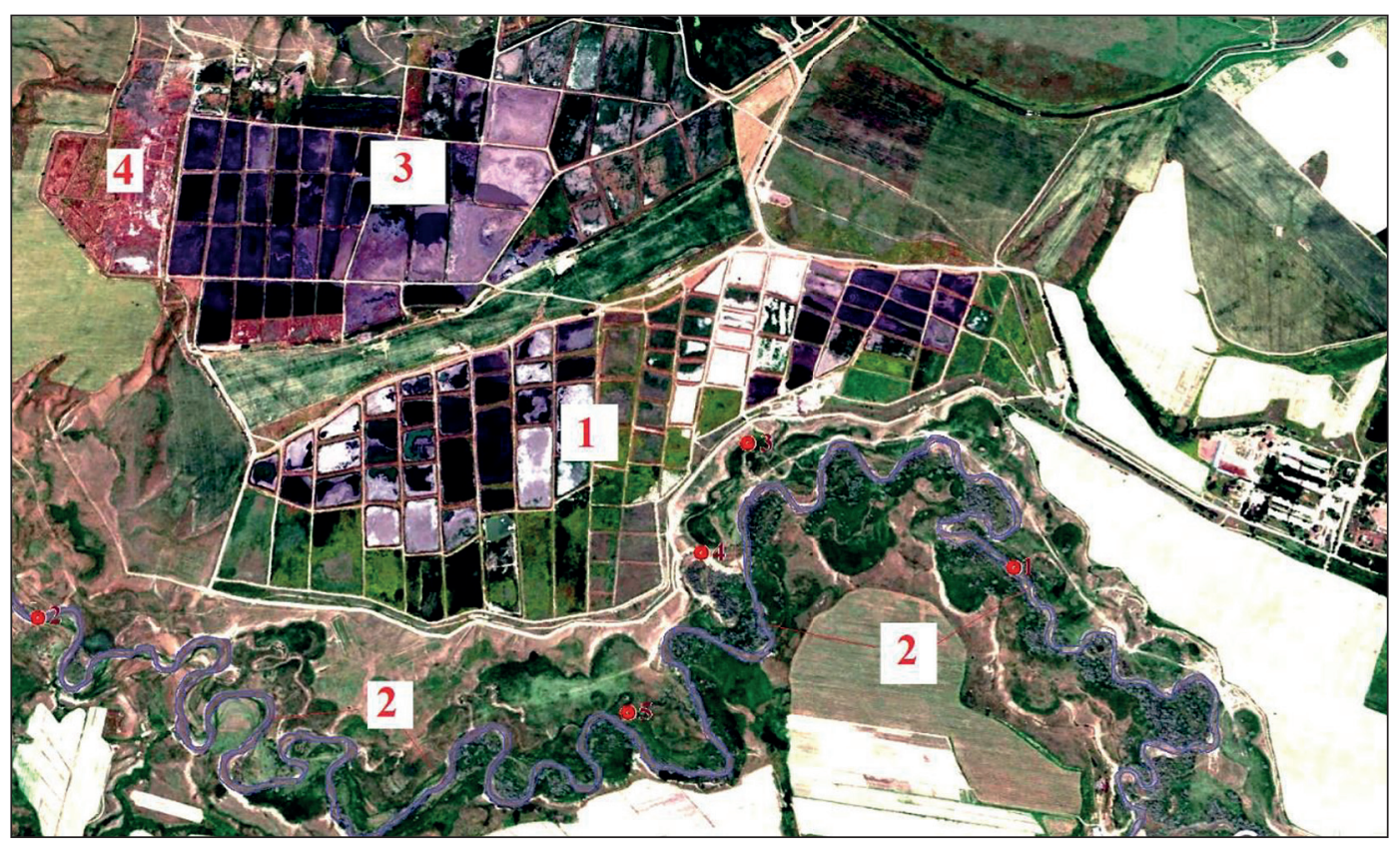

Fig. 5. Appearance of sludge beds showing sampling point:

1 - Silt area; 2 - Bolshaya Almatinka River; 3 - filtration fields; 4 - dried sediment site; $1,2,3,4,5$ - sampling points

capacity. Therefore, excess sludge was returned to the distribution chamber of the primary sedimentation tanks to increase the efficiency of aerobic biological wastewater treatment in 2006. This means that the excess activated sludge is pumped by the pumps of the main pumping station into the distribution bowl (chamber) of the primary radial sedimentation tanks.

Some measurement results of the amount of excess sludge pumped into the distribution chamber of the primary sedimentation tanks are shown in Table 3.
The primary radial sedimentation tank at the Almaty aeration station is a circular tank with a conical bottom $(i=0.022)$. Technical characteristics of primary radial sedimentation tanks of the Almaty aeration station are given in Table 4.

Aeration plants use aeration tanks with return sludge regeneration for complete biological wastewater treatment. The aeration tanks that are part of the treatment plant system, operate on the displacer principle: incoming water displaces treated water from the plant. Technical characteristics of the aeration tanks are given in Table 5. 
Table 2. Summary results of analyses of the Big Almatinka River water and groundwater from the Silt area

\begin{tabular}{|c|l|c|c|c|c|c|}
\hline \multirow{2}{*}{ No. Indicators } & \multicolumn{5}{c|}{ Content in samples, mg/l } \\
\cline { 3 - 7 } & & No. 1 & No. 2 & No. 3 & No. 4 & No. 5 \\
\hline 1. & Suspended substance & 5.0 & 7.0 & 50.0 & 80.0 & 10.0 \\
\hline 2. & Biochemical oxygen demand -5 day test & 3.0 & 4.0 & 2.7 & 2.4 & 2.7 \\
\hline 3. & Chemical oxygen demand & 4.0 & 16.0 & 10.0 & 10.0 & 4.5 \\
\hline 4. & Nitrites & 0.11 & 0.36 & 0.04 & 0.112 & 0.168 \\
\hline 5. & Nitrates & 24.5 & 43.6 & 8.5 & 20.0 & 10.0 \\
\hline 6. & Calcium & 24.0 & 34.0 & 96.0 & 56.0 & 56.1 \\
\hline 7. & Magnesium & 1.2 & 7.3 & 77.0 & 81.5 & 81.5 \\
\hline 8. & Phosphates & 0.8 & 1.7 & 8.5 & 8.2 & 3.8 \\
\hline 9. & Petroleum products & 0.06 & 0.08 & 0.6 & 0.8 & 0.03 \\
\hline 10. & Chlorides & 10.6 & 11.5 & 24.0 & 28.0 & 8.0 \\
\hline 12. & Sulfates & 28.8 & 37.0 & 120.0 & 427.0 & 103.0 \\
\hline 13. & Hydrocarbonates & 109.8 & 134.2 & 274.5 & 750.0 & 463.6 \\
\hline 14. & Copper & 0.06 & 0.06 & 0.46 & 0.39 & 0.09 \\
\hline 15. & Iron & 0.3 & 0.42 & 0.31 & 4.2 & 0.5 \\
\hline 16. & Zinc & 0.06 & 0.09 & 0.46 & 0.39 & 0.9 \\
\hline 17. & Bromine & 0.08 & 0.12 & 0.21 & 0.29 & 0.07 \\
\hline 18. & Strontium & 0.44 & 0.54 & 5.85 & 6.95 & 1.02 \\
\hline
\end{tabular}

The results of hydrobiological analysis of activated sludge in 2020 are shown in Table 6. As shown in the table, the results of hydrobiological analysis of activated sludge specify that the return of excess sludge to the primary sedimentation tank allows the retention of active sludge indicators at a normal level.

The return activated sludge circulates uninterruptedly in the system Regenerator - Aeration Tank - Film Mixing Channel - Sewage Channel Regenerator, due to hydrostatic pressure at certain stages of the path and lifting to a height allowing for further circulation, by axial pumps. The return sludge dose is on average $3.4 \mathrm{~g} / 1$. Secondary sedimentation tanks are used to retain activated sludge that comes with treated water from the aeration tanks. Technical characteristics: type of tanks - typical secondary radial sedimentation tank; number of tanks - 12 pcs; tank diameter $\mathrm{D}=40 \mathrm{~m}$; hydraulic depth $-\mathrm{H}=4.35 \mathrm{~m}$; depth of screening zone $-\mathrm{P}=3.65 \mathrm{~m}$; height of sludge zone $-\mathrm{H}=0.7 \mathrm{~m}$. Further, the purified water, after complete biological treatment, through an earthen canal (49 km long) is sent to the Sorbulak storage lake, or, through a special water divider, to the system of storage reservoirs of the Right-Bank Sorbulak Canal (RBSC). Figure 6 shows the external view of the sewage disposal of the aeration station in Almaty.

Table 3. Measurement results of the amount of excess sludge pumped into the distribution chamber of the primary sedimentation tanks

\begin{tabular}{|c|c|c|c|c|c|}
\hline Date & Quantity, $\mathrm{m}^{3}$ & Date & Quantity, $\mathrm{m}^{3}$ & Date & Quantity, $\mathrm{m}^{3}$ \\
\hline 25.02 .2020 & 7620.0 & 16.03 .2020 & 3360.0 & 19.05 .2020 & 6020.0 \\
\hline Date & Quantity, $\mathrm{m}^{3}$ & Date & Quantity, $\mathrm{m}^{3}$ & Date & Quantity, $\mathrm{m}^{3}$ \\
\hline 10.07 .2020 & 4300.0 & 19.08 .2020 & 5160.0 & 20.09 .2020 & 6450.0 \\
\hline
\end{tabular}

Table 4. Technical characteristics of primary radial sedimentation tanks

\begin{tabular}{|c|c|c|c|}
\hline Number of sedimentation tanks & $\begin{array}{c}\text { Design throughput of sedimentation } \\
\text { tank at 1.5-hour sedimentation } \\
\mathrm{m}^{3} / \text { hour }\end{array}$ & $\begin{array}{c}\text { Sedimentation tank diameter } \\
\mathrm{m}\end{array}$ & $\begin{array}{c}\text { Hydraulic depth } \\
\mathrm{m}\end{array}$ \\
\hline $\begin{array}{c}\text { 12 pieces (4 sedimentation } \\
\text { tanks per group) }\end{array}$ & 3053 & 40 & 4 \\
\hline $\begin{array}{c}\text { The volume of sedimentation } \\
\text { tank flow area, } \mathrm{m}^{3}\end{array}$ & The volume of sediment area, $\mathrm{m}^{3}$ & $\begin{array}{c}\text { Diameter of inlet and outlet } \\
\text { piping, } \mathrm{mm}\end{array}$ & Sludge scraper type \\
\hline 4580 & 710 & 1200 & IPR-40 \\
\hline
\end{tabular}


Wastewater has been discharged into the Sorbulak storage lake by gravity due to the natural relief of the area since 1972. The Sorbulak storage lake is located $35 \mathrm{~km}$ southwest of Almaty in the Ili district of the Almaty region. In terms of area, it is the largest wastewater sedimentation tank in the CIS and one of the largest in the world. At the level of the normal water surface of the Sorbulak storage lake (620.5 meters), the mirror area is $58 \mathrm{~km}^{2}$, the maximum length is $35 \mathrm{~km}$, the width is up to $15 \mathrm{~km}$, and the maximum depth is up to $31 \mathrm{~m}$. The capacity of the Sorbulak storage lake at the maximum water surface mark (622 meters) is 996.5 million $\mathrm{m}^{3}$. We took samples from wastewater in the Sorbulak storage lake. The average indicators of the chemical composition of wastewater are presented in Table 7.

The $\mathrm{pH}$ in the Sorbulak storage lake, according to the analysis results, was minimally noted at 7.7 and reached a maximum of 9.2 that indicates an alkaline environment of the wastewater storage. According to the $\mathrm{BOD}_{5}$ indicator, Sorbulak water mainly refers to dirty waters. At the same time, the highest $\mathrm{BOD}_{5}$ values were recorded during the warm period. The presence of exceeding the standards for chemical indicators in the water of the Sorbulak storage lake is possibly related to the historical contamination of the

Table 5. Technical characteristics of the aeration tanks

\begin{tabular}{|c|c|}
\hline Name of indicators & Value of indicators \\
\hline Aeration tank unit No. 1 & Experimental, deep-water, consisting of sections $A$ and $B$ \\
\hline Number of aeration tanks & 2 units \\
\hline Section volume & $V=63140 \mathrm{~m}^{3}$ \\
\hline Block dimensions (plan) & $110 \times 164 \mathrm{~m}$ \\
\hline Dimensions of one section & $110 \times 80 \mathrm{~m}$ \\
\hline Working depth & $\mathrm{H}=7.0 \mathrm{~m}$ \\
\hline Number of corridors per section & 8 pcs. \\
\hline Design (planned) capacity of the unit & 320 thousand $\mathrm{m}^{3}$ per day \\
\hline Aeration tank No. 1 & type four-corridor, consisting of aeration tanks No.1, No.2, No.3, No.4 \\
\hline The volume of one aeration tanks & $V=25000 \mathrm{~m}^{3}$ \\
\hline The volume of one regenerator & $V=6250 \mathrm{~m}^{3}$ \\
\hline Block dimensions (plan) & $144 \times 144 \mathrm{~m}$ \\
\hline Dimensions of one aeration tanks & $144 \times 36 \mathrm{~m}$ \\
\hline Working depth & $\mathrm{H}=5.0 \mathrm{~m}$ \\
\hline Number of corridors in one aeration tanks & 4 pcs. \\
\hline Design (planned) capacity of the unit & 320 thousand $\mathrm{m}^{3}$ per day \\
\hline
\end{tabular}

Table 6. Results of hydrobiological analysis of activated sludge in 2020

\begin{tabular}{|c|c|c|c|c|c|c|}
\hline \multirow{3}{*}{ Indicators } & \multicolumn{6}{|c|}{ Aeration tanks } \\
\hline & \multicolumn{4}{|c|}{ Typical } & \multicolumn{2}{|c|}{ Experimental } \\
\hline & No. 1 & No. 2 & No. 3 & No. 4 & $31 \mathrm{~A}$ & 31B \\
\hline Sludge dose, g/l & $\frac{0.6-3.4}{1.7}$ & $\frac{1.0-2.5}{1.4}$ & $\frac{0.4-2.9}{1.8}$ & $\frac{0.6-3.5}{1.6}$ & - & $\frac{0.4-2.8}{1.5}$ \\
\hline Sludge index, $\mathrm{ml} / \mathrm{g}$ & $\frac{78-182}{123}$ & $\frac{81-140}{111}$ & $\frac{87-146}{119}$ & $\frac{86-162}{121}$ & - & $\frac{82-153}{120}$ \\
\hline Ash content, \% & $\frac{23-42}{29}$ & $\frac{18-40}{28}$ & $\frac{19-61}{30}$ & $\frac{20-40}{29}$ & - & $\frac{20-54}{31}$ \\
\hline Dissolved $\mathrm{O}_{2}$, mg/l & $\frac{0.17-5.74}{2.31}$ & $\frac{0.29-7.21}{2.83}$ & $\frac{0.25-7.56}{2.27}$ & $\frac{0.09-5.5}{1.88}$ & - & $\frac{0.04-4.0}{1.84}$ \\
\hline \multirow{3}{*}{ Indicators } & \multicolumn{6}{|c|}{ Regenerators } \\
\hline & \multicolumn{3}{|c|}{ Typical } & \multicolumn{3}{|c|}{ Experimental } \\
\hline & No. 1 & No. 2 & No. 3 & No. 4 & $31 \mathrm{P}(\mathrm{a})$ & $31 \mathrm{P}(\mathrm{b})$ \\
\hline Sludge dose, g/l & $\frac{1.8-6.6}{3.6}$ & $\frac{0.2-5.5}{3.1}$ & $\frac{0.5-6.1}{3.5}$ & $\frac{1.3-6.4}{3.6}$ & - & $\frac{0.8-6.5}{3.2}$ \\
\hline $\begin{array}{l}\text { Dissolved } \\
\mathrm{O}_{2}, \mathrm{mg} / \mathrm{l}\end{array}$ & $\frac{0.03-3.99}{1.21}$ & $\frac{0.03-7.76}{1.73}$ & $\frac{0.04-7.75}{1.32}$ & $\frac{0.02-3.5}{1.08}$ & - & $\frac{0.007-3.08}{1.01}$ \\
\hline
\end{tabular}

Note: Numerator is the minimum-maximum value of the indicator; the denominator is the average value of the indicator. 


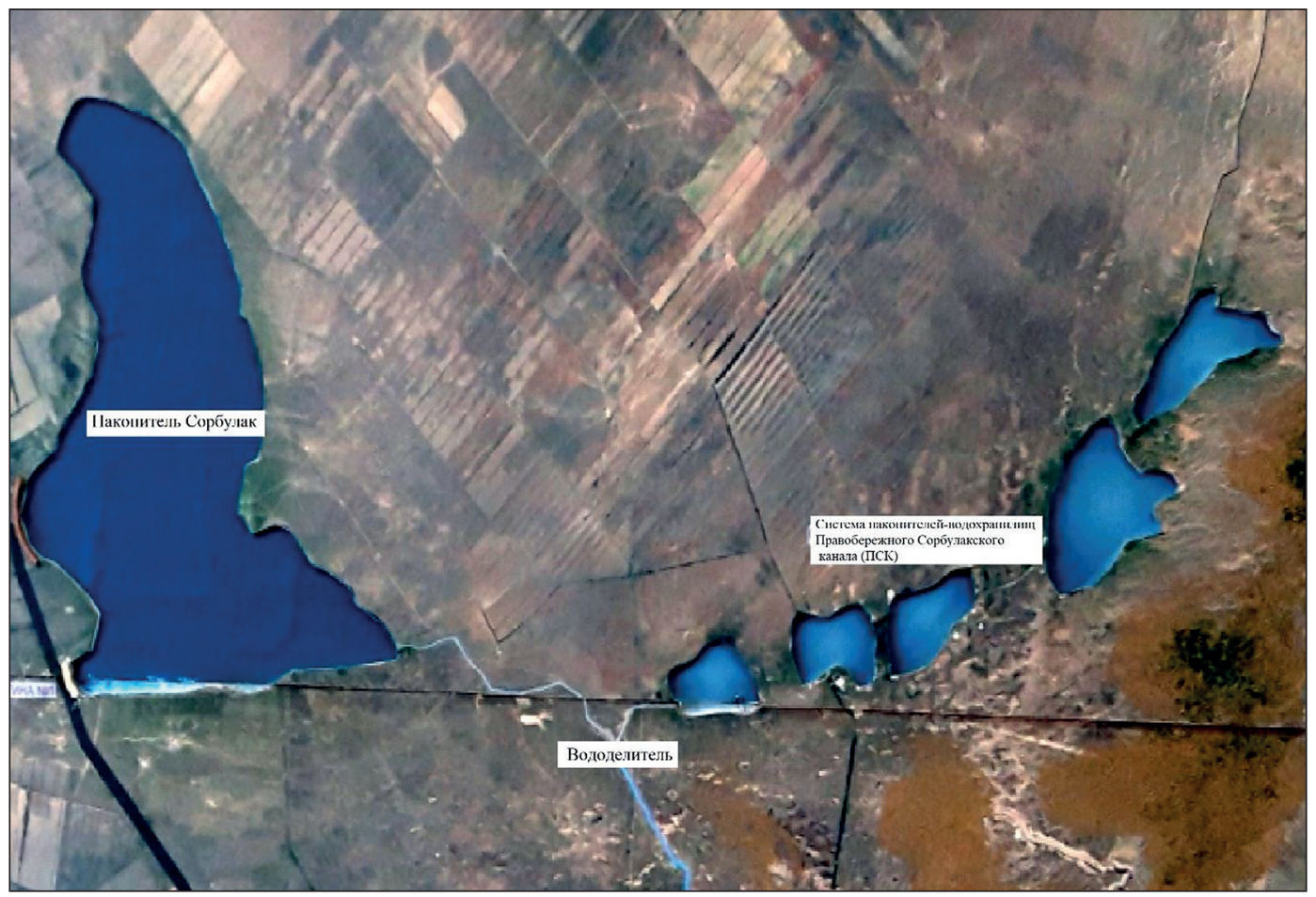

Fig. 6. Exterior view of wastewater disposal at the aeration station in Almaty

Sorbulak storage lake that has been in operation for 49 years. After decontamination in the chlorination room, purified and additional purified water in bio ponds from the RBSC storage tanks can be discharged through an emergency discharge channel into the Ili River. Emergency discharge into the Ili river is designed to prevent overfilling of the reservoirs of Sorbulak and RBSC. The results of the analysis of the water balance for 2020 are shown in Table 8.

As follows from Table 8, in connection with an increase in the volume of treated wastewater

Table 7. Average indicators of the chemical composition of wastewater in the Sorbulak storage lake

\begin{tabular}{|l|c|}
\hline \multicolumn{1}{|c|}{ Indicators, $\mathrm{mg} / \mathrm{l}$} & $\begin{array}{c}\text { In the Sorbulak } \\
\text { storage lake }\end{array}$ \\
\hline $\mathrm{pH}$ value $(\mathrm{pH})$ & 8.2 \\
\hline Mineralization, $\mathrm{mg} / \mathrm{l}$ & 1116.4 \\
\hline $\begin{array}{l}\text { Biochemical oxygen demand - 5-day } \\
\text { test, } \mathrm{mg} / \mathrm{l}\end{array}$ & 8.3 \\
\hline Chemical oxygen demand, $\mathrm{mg} / \mathrm{l}$ & 36.9 \\
\hline Suspended substance, $\mathrm{mg} / \mathrm{l}$ & 24.8 \\
\hline Sulphates, $\mathrm{mg} / \mathrm{l}$ & 340.6 \\
\hline Chlorides, $\mathrm{mg} / \mathrm{l}$ & 251.1 \\
\hline Hydrogen sulfide, $\mathrm{mg} / \mathrm{l}$ & 0.34 \\
\hline Ammonium nitrogen, $\mathrm{mg} / \mathrm{l}$ & 10.7 \\
\hline Nitrite nitrogen, $\mathrm{mg} / \mathrm{l}$ & 0.8 \\
\hline Nitrate nitrogen, $\mathrm{mg} / \mathrm{l}$ & 6.3 \\
\hline Phosphates, $\mathrm{mg} / \mathrm{l}$ & 7.8 \\
\hline
\end{tabular}

intake for irrigation of industrial crops, the tightly controlled water balance of the Sorbulak and RBSC storages makes it possible not to discharge into the Ili River. The last discharge of part of the treated wastewater into the Ili River was performed in 2006. Table 9 below shows the hydrochemical treatment quality data that have been achieved by 2020 .

As the table shows, the wastewater contains rather high concentrations of organic matter due to a significant drop in hydraulic load, with treatment quality above the established concentrations of maximum permissible discharge.

\section{CONCLUSIONS}

The analyses obtained specify that the groundwater from the areas adjacent to the sludge beds has a high level of contamination and that the water from the sludge beds to some extent contaminates the water of the Bolshaya Almatinka River with various chemical elements. Besides, the results obtained during the work show that pretreatment of wastewater with excess sludge in the primary sedimentation tank can significantly reduce a load of organic pollutants on the aerobic biological treatment section and increase the efficiency of the treatment plant as a whole. 
Table 8. Results of the analysis of the water balance for 2020

\begin{tabular}{|c|c|c|c|c|c|c|c|c|c|}
\hline \multirow{3}{*}{ Quarter } & \multirow{3}{*}{$\begin{array}{l}\text { Passed through } \\
\text { the mechanical } \\
\text { cleaning, } \\
\text { thousand } \mathrm{m}^{3}\end{array}$} & \multirow{3}{*}{$\begin{array}{c}\text { Received for } \\
\text { biological } \\
\text { treatment, } \\
\text { thousand } \mathrm{m}^{3}\end{array}$} & \multirow{3}{*}{$\begin{array}{c}\text { Received by } \\
\text { the divider, } \\
\text { thousand } \\
\mathrm{m}^{3}\end{array}$} & \multicolumn{3}{|c|}{ Sorbulak storage lake } & \multicolumn{2}{|c|}{ RBSC } & \multirow{3}{*}{$\begin{array}{l}\text { Discharge } \\
\text { into the } \\
\text { Ili River, } \\
\text { thousand } \mathrm{m}^{3}\end{array}$} \\
\hline & & & & \multicolumn{2}{|c|}{ Admission } & \multirow{2}{*}{$\begin{array}{c}\begin{array}{c}\text { For } \\
\text { watering }\end{array} \\
\begin{array}{c}\text { Thousand } \\
\mathrm{m}^{3}\end{array} \\
\end{array}$} & \multirow{2}{*}{\begin{tabular}{c|} 
Admission \\
$\begin{array}{c}\text { Thousand } \\
\mathrm{m}^{3}\end{array}$ \\
\end{tabular}} & \multirow{2}{*}{$\begin{array}{c}\text { For } \\
\text { watering } \\
\begin{array}{c}\text { Thousand } \\
\mathrm{m}^{3}\end{array} \\
\end{array}$} & \\
\hline & & & & $\begin{array}{c}\text { Thousand } \\
\mathrm{m}^{3}\end{array}$ & Mark & & & & \\
\hline 1 & 34342.768 & 34008.123 & 32683.39 & 26808.2 & 618.86 & & 5875.2 & 0 & 0 \\
\hline 2 & 32266.80 & 31674.136 & 23420.45 & 10605.7 & 618.91 & & 12743.13 & 7495.2 & 0 \\
\hline 3 & 32929.401 & 32568.078 & 13366.08 & 0 & 618.37 & 17316.2 & 13366.08 & 18740.16 & 0 \\
\hline 4 & 32749.338 & 32402.435 & 30787.78 & 11639.8 & 618.38 & & 19147.96 & 406.08 & 0 \\
\hline Total & 132288.307 & 130652.77 & 100257.7 & 49125.31 & 618.38 & 17316.2 & 51132.38 & 26641.4 & 0 \\
\hline
\end{tabular}

Table 9. Indicators of the quality of cleaning achieved by 2020

\begin{tabular}{|c|c|c|c|c|c|}
\hline Indicators, mg/l & $\begin{array}{l}\text { Incoming } \\
\text { water }\end{array}$ & $\begin{array}{l}\text { Clarified } \\
\text { water }\end{array}$ & $\begin{array}{l}\text { Purified } \\
\text { water }\end{array}$ & $\begin{array}{l}\text { Maximum of permissible } \\
\text { discharges to Sorbulak } \\
\text { storage and RBSC storage }\end{array}$ & $\begin{array}{l}\text { Maximum of permissible } \\
\text { discharges for irrigation }\end{array}$ \\
\hline $\mathrm{pH}$ value $(\mathrm{pH})$ & 7.4 & 7.5 & 7.6 & & $6-9$ \\
\hline Suspended substance, mg/l & 506.9 & 114.7 & 16.9 & 27.4 & $\mathrm{~S}_{\text {actual }}+5,0$ \\
\hline Ammonium nitrogen, mg/l & 16.1 & 13.4 & 6.9 & 18.0 & \\
\hline Nitrite nitrogen, mg/l & 0.11 & 0.1 & 0.61 & 1.5 & 3.3 \\
\hline Nitrate nitrogen, mg/l & 0.18 & 0.26 & 2.49 & 5.0 & 45.0 \\
\hline $\begin{array}{l}\text { Biochemical oxygen demand } \\
-5 \text { day test, } \mathrm{mg} / \mathrm{l}\end{array}$ & 461.3 & 134.9 & 10.0 & & 10.0 \\
\hline TBOD, mg/l & 834.8 & 199.1 & 12.4 & 16.5 & \\
\hline Chemical oxygen demand, mg/l & 943.1 & 250.9 & 30.0 & 35.0 & 35.0 \\
\hline Iron, mg/l & 2.09 & 1.06 & 0.43 & 2.5 & 0.3 \\
\hline Cadmium, mg/l & 0.0028 & 0.0013 & 0.0004 & & 0.005 \\
\hline Calcium, mg/l & 66.57 & 60.49 & 56.56 & 81.0 & 150.0 \\
\hline Cobalt, mg/l & 0.01 & 0.003 & 0.0005 & 0.005 & 0.1 \\
\hline Magnesium, mg/l & 14.61 & 13.39 & 12.39 & 28.0 & 100.0 \\
\hline Copper, mg/l & 0.017 & 0.0099 & 0.0034 & 0.015 & 1.0 \\
\hline Nickel, mg/l & 0.0043 & 0.0028 & 0.0011 & 0.016 & 0.1 \\
\hline Hydrogen sulphide, mg/l & 5.16 & 4.31 & 0.44 & 0.5 & \\
\hline Lead, mg/l & 0.0033 & 0.0016 & 0.0007 & 0.166 & 0.05 \\
\hline $\begin{array}{l}\text { Synthetic surface active } \\
\text { substance, } \mathrm{mg} / \mathrm{l}\end{array}$ & 3.75 & 2.93 & 0.28 & 0.6 & 0.5 \\
\hline Strontium, mg/l & 0.4228 & 0.3858 & 0.3427 & 0.73 & \\
\hline Sulphates, mg/l & 73.3 & 65.7 & 57.1 & 100.0 & 600.0 \\
\hline Phosphates, mg/l & 10.2 & 8.0 & 3.7 & 7.3 & 1.0 \\
\hline Fluorine, mg/l & 1.04 & 0.95 & 0.89 & 1.3 & 1.5 \\
\hline Chlorides, mg/l & 99.6 & 95.2 & 88.3 & 103.0 & 350.0 \\
\hline Chromium, mg/l & 0.014 & 0.002 & 0.0004 & 0.024 & 0.55 \\
\hline Zinc, mg/l & 0.027 & 0.017 & 0.0095 & 0.134 & 1.0 \\
\hline Mineralisation, mg/l & 590.22 & 554.05 & 438.92 & & 2000.0 \\
\hline
\end{tabular}

Pollution of wastewater entering the aeration tank decreases and the concentration of suspended solids decreases to $114.7 \mathrm{mg} / \mathrm{l}, \mathrm{BOD}_{5}-$ to $134.9 \mathrm{mg} / \mathrm{l}$. Under these conditions, it may be possible to implement a highly efficient biological process of oxidation of impurities in the aeration tank and the formation of well flocculated and easily settling in the secondary sedimentation tank biomass of activated sludge. Thus, the results of statistical processing of obtained data allow considering the above methods as very effective and technically economical ones when introducing them into the practice of building new and reconstruction of operating sewage treatment facilities.

At the same time, it should be borne in mind that the recycling of significant amounts of sludge biomass, highly contaminated with organic matter, results in additional pollution of raw sewage 
by suspended solids and increases the pollution load on the activated sludge, functioning in the aeration tank. The design of the treatment systems, therefore, needs to optimally match the operation of the sludge recirculation line with the initial contaminant load coming into the aeration tank with the wastewater fed into the plant.

\section{Acknowledgments}

We acknowledge the support of the Ministry of Education and Science of the Republic of Kazakhstan. The work was performed with the financial support of the Committee of Science of the Ministry of Education and Science of the Republic of Kazakhstan (grant AP08855852). The authors are also grateful to the staff of the State Communal Enterprise "Almaty Su" for their assistance in laboratory research and the sampling process.

\section{REFERENCES}

1. Andreev S.Y., Grishin B.M., Maksimov S.V., Titov E.A., Nikolaev V.V. 2006. Intensification of the mass transfer process in aeration facilities of biological wastewater treatment as a factor influencing the improvement of secondary settling tanks. News of higher educational institutions. Construction, 11-12, 56-60.

2. Burger R., Diehl S., Nopens I. 2011. A consistent modelling methodology for secondary settling tanks in wastewater treatment. Water Research. 45(6), 2247-2260.
3. Chen J., Luo J., Luo Q., Pang Z. 2018. Wastewater Treatment: Application of New Functional Materials De Gruyter, China Environment Publishing Group Co., Ltd., 324.

4. Directive 2000/60/EC of the European Parliament and of the Council of 23 October 2000 establishing a framework for Community action in the field of water policy. URL: http:// www.caresd.net/iwrm/ new/doc/direct.pdf (reference date: 28.10.2013)

5. Droste R., Gehr R. 2019. Theory and Practice of Water and Wastewater Treatment 2d Edition. - Hoboken, USA: JohnWiley\&Sons,Inc., 992.

6. Environmental Code of the Republic of Kazakhstan dated January 2, 2021, LEGISLATION OF THE RK. Nur-Sultan, 400(6), 399.

7. Guiding normative document 01.01.03-94. 1994. Rules of surface water protection of the Republic of Kazakhstan. Almaty, 21.

8. Lovett D.A., et al. 1984. Activated sludge treatment of abatoir wastewaters. I. Influence of sludge and feeding pattern. Waster Recearch, 18(4), 429-434.

9. Material from Wikipedia - the free encyclopedia [Electronic resource] https://ru.wikipedia.org/wiki/ Алма-Ата

10. Technological regulations for the operation of the Aeration Plant in Almaty. 2013. Almaty, 251.

11. Vaxelaire J., Ce'zac P. 2004. Moisture distribution in activated sludges: a review. Water Research. 38, 2215-2230.

12. Werther J., Ogada T. 1999. Sewage sludge combustion. Progress in Energy and Combustion Science, 25, 55-116.

13. Zhmur N.S. 2003. Technological and biochemical processes of wastewater treatment at facilities with aerotanks. AKVAROS, 512. 